\title{
Iranian Students' Self Efficacy and Their Language Achievements
}

\author{
Atefeh Nasrollahi \\ Islamic Azad University, Ayatollah Amoli Branch, Amol, Mazandaran, Iran \\ Hamed Barjasteh \\ Islamic Azad University, Ayatollah Amoli Branch, Amol, Mazandaran, Iran
}

\begin{abstract}
Many studies have examined the function of self efficacy in academic achievement, though as Pajares (2000) mentioned the relation of language achievement and self efficacy has not been studied well and there has been small research in this regard. This made the researcher to investigate the relationship between Iranian students' language achievements and their self efficacy. It also studied the variations of Iranian students' self efficacy and their majors. Besides, it explores the differences between students' majors and their language achievements. 112 students from Islamic Azad University Babol Branch, Islamic Azad University Ghaemshahr Branch, and Babol University of Medical sciences were chosen for the sample of present study. In order to measure students' language proficiency, Michigan Test of English Language Proficiency (MTELP) was administered. The self-efficacy questionnaire which was an adaptation of Bandura's questionnaire included 40 items with subsequent 5-point Likert-scale response choices. The result of study shows a positive relation between self efficacy and Iranian students' language proficiency. This study also found that students' major will have an effect on both language proficiency and self efficacy.
\end{abstract}

Index Terms—academic achievement, language achievement, self efficacy

\section{INTRODUCTION}

It is apparent that learners' affective variables have a key role in students' success. Some scholars even believed affective variables have influenced success or failure of foreign language learning even more than aptitude (Chastain, 1988). Among affective variables self efficacy is recognized to have an essential role in academic success of students. Bandura (1993) argues that efficacy beliefs affect the way people feel, think and behave. "In social cognitive theory, people must develop skills in regulating the motivational, affective, and social determinants of their intellectual functioning as well as the cognitive aspects" (p. 136). Pajares (2000) believed self efficacy is a marvelous predictor of individual behavior and functioning.

Self-efficacy has been used in research in different social, political and academic settings. However as Pajares(2000) concerned there are few researches in the relation of second language achievement and self efficacy. The current study intended to study the relation between self efficacy and foreign language achievement in Iranian university students.

\section{REVIEW OF RELATED LITERATURE}

Bandura in 1970s, became conscious that a key component was absent from the prevailing learning theories of the day, and his own social learning theory. (Pajares, 2002). Rejecting the behaviorist's indifference to self- processes, Bandura (1977) was able to identify that important missing element, self-beliefs. He believed that each person makes self perceptions of his abilities which are useful for his perusing goals and for controlling they have over their environment.

According to Pajares (2002), these attitudes make a self system with explicit, progressive, symbolizing, self reflective, and self regulatory competences, and individual behavior is the outcome of interaction between this personal system and external sources of influence. Pajares and Schunk (2001) state that in sociocognitive perspective, an individual is considered as active and self regulating agent not a passive one controlled by other factors. Bandura (1989) mentions that"persons are neither autonomous agents nor simply mechanical conveyors of animating environmental influences. Rather, they make casual contribution to their own motivation and action within a system of triadic reciprocal causation" (p.1175). This, in turn, can be the reflection of Bandura's (1986) notion of reciprocal determinism which refers to interaction of:

behavioral variables (what people actually do)

- environmental variables (the setting in which the behavior occurs), and

personal/cognitive variables (how the person thinks about, perceives, or expects events to occur).

Then, Bandura changed the name of his theory from social learning to social cognitive to emphasize the serious role of human cognition in people's lives. Pajares (2002) states that Bandura's Social Cognitive Theory is different from others theories of human behavior which overemphasizes the function of environmental or biological aspects. Bandura 
(1986) believed a theory which rejects thoughts can control acts cannot explain complex human behavior. What people think, believe, and feel influences their behavior. The natural and extrinsic effects of their actions, somehow establish their thought models and their succeeding actions. The fulfillments individuals achieve from what they do are established to a great degree by their self evaluative standards.

\section{A. Definition}

Bandura (1977) defines self efficacy as "people's judgments of their capabilities to organize and execute courses of action required to attain designated types of performance" (p. 174). Bandura (1977) emphasized on self efficacy, which operates what individuals choose to do; their level of attempt and perseverance when encountering troubles; and the consequent act. It is a dynamic, many sided belief system that varies in different circumstances and activities.

Bandura (1986) argues that self- efficacy is a general belief about one's capabilities to successfully control crucial actions in life. Spratt, Humphreys, and Chan (2002) state that self efficacy is a motivational construct which influence learners to autonomous behavior. It refers to an individual's beliefs that he has the capability to attain a certain level of performance and attainment.

Pajares (2002) states that according to Bandura's social cognitive theory, individuals poses a self-system that permit them to use a measure control over their thoughts, feelings, motivation, and actions. Self efficacy according to Bandura's social cognitive theory, individuals possess a self-system that enable them to exercise a measure of control over their thoughts, feelings, motivation, and actions. Self efficacy beliefs can change human functioning by providing individuals with the ability to influence their own cognitive processes and actions and so modify their surroundings. Bandura (1997) claimed self efficacy has a significant role in human functions. He stated "People's level of motivation, affective states, and actions are based more on what they believe than on what is objectively true" (p. 2). That is the reason why individuals functioning can be estimated by the beliefs about their abilities rather than by what they are truly capable of doing, in fact theses beliefs can help to decide what individuals can do with their knowledge and skills

\section{B. Sources of Self Efficacy}

Bandura (1986) considered four sources of self belief: Mastery Experiences (past successes/ failures affect our current level of self-efficacy in a specific context), Vicarious Experiences (seeing others perform a behavior successfully leads us to believe in our own capability to do it, especially when these others are similar to ourselves), Verbal/Social Persuasion (people's self-efficacy beliefs are enhanced if they are told and convinced that they can succeed), Emotional and Physiological State (when you are physically fit or in a positive mood your efficacy will be enhanced). Bandura (1993) argues that the various effects that self efficacy beliefs create is done through the following four key procedures.

- Cognitive Process: Most of our actions are initially shaped in our thought. Self-efficacious ones visualize success that provides positive guides and supports for performance. Conversely, those who doubt their efficacy imagine failure which makes things go wrong.

- Motivational Process: self efficacy beliefs can also affect motivation. These beliefs have a important function in developing motivation. The majority of our motivation is cognitively shaped.

Through the exercise of forethought people motivate themselves, guide their actions, and form beliefs about what they can do.

- Affective Process: individuals' beliefs about what they are able to do influence the amount of tension and depression they would encounter in frightening or complex circumstances and also the level of motivation

- Selection Process: Judgments of personal efficacy influence people's choice of environments and activities. Individuals also break away from activities and conditions which seem to be beyond their abilities

\section{Efficacious versus Inefficacious People}

Bandura (1995) claims high self efficacious learners monitor their performance, endure longer, and solve the problems better than low self efficacious students. Pajares (2002) argues that high self efficacious individuals have the following characteristics:

a) They don't see complex activities as a thread to evade rather they move toward it as a demanding activity to be mastered

b) Their inherent interest in doing tasks is superior, their goals are more demanding, and they keep up their attempt even in the face of difficulties

c) They would recover their self belief rapidly after failures, and would see failures due to their own inadequate attempts or their own lack of knowledge or skills, in fact they do not look for external elements

d) They are also not nervous and are calmer in accomplishing complex tasks.

On the contrary, low self efficacious individuals consider tasks much harder than what they actually are, and this will increase their anxiety, tensions, depression and a give them weaker view for solving problem (Pajares, 2002). Bandura (1986) states that "people who hold a low view of themselves will credit their achievements to external factors, rather than to their own capabilities" (p.402). "If self efficacy is lacking, people tend to behave weekly, even though, they know what to do" (p. 425). High self efficacious people would think, feel and act in a different way from low self efficacious ones, and believes that they can make their own futures. Bandura (1993) states the following: 
"Students who have a high sense of academic and self-regulative efficacy behave more prosodically, are more popular, and experience less rejection by their peers than do students who believe they lack these forms of academic efficacy. Moreover, a low sense of academic and self-regulatory efficacy is associated with emotional irascibility, physical and verbal aggression, and ready disengagement of moral self-sanctions from harmful conduct. The impact of student's disbelief in their academic efficacy on socially discordant behavior becomes stronger as they grow older." (p. 138)

Pajares (2005) argues that high self efficacious students try more, endure longer with encountering problems, are more optimistic, and are less nervous. Highly self efficacious students consider themselves capable of doing academic tasks using different kinds of cognitive and metacognitive strategies while inefficacious ones do not believe in their capability. Bandura (1997) proposes that self efficacy refers to the state of being able to control challenging environmental demands through taking adaptive action. Individuals who trust themselves and assume they have their own resources to succeed exhibit a greater effort and perseverance. Bandura (1997) states that self-efficacy refers to the obvious benefits of enhancing students' confidence in their capacities.

\section{Distinctive Features of Academic Self-efficacy}

According to Bandura (1977) academic self efficacy is described as personal judgment of one's abilities to manage and carrying out different actions to reach special types of educational performance. Academic self-efficacy predicts academic performance. In fact there is a mutual relationship between self efficacy and academic achievements. Dewitz and Walsh (2002) state that self efficacy beliefs are considerably related to academic choices and performances. Self efficacy beliefs are positively related to action, perseverance, and expected results. Academic self efficacy is related with students' satisfactions. Students with greater self efficacy seem to be more pleased with college life. Individuals with higher self efficacy will have higher satisfaction. Students with greater self efficacy in particular area will have better performance in that particular area. Pajares (2005) uttered that academic self efficacy will enhance students' strategy use. He mentioned that self efficacy affects cognitive strategy use and self regulation by using metacognitive strategies.

Schunk (1991) states that academic self-efficacy can be defined as person's self assurance in their own capabilities to successfully perform academic activities at a designed level. Jing (2006) states that self-efficacy in language learning can be perceived as students' judgment about their capabilities and their improvement in specific situations they are learning the language.

\section{E. Distinctive Features of Self-efficacy}

Zimmerman \& Cleary (2006) named four main features of self efficacy. First, it focuses on proposed abilities to perform a task rather than on behavior or psychological characters. In fact self efficacy deals with "how well can I do something?' rather than "what am I like?". Next, self efficacy beliefs are domain-specific, context-specific, and activity specific. In context- specific, for example an individual may shows a low self efficacy for learning math in a competitive classroom context than in cooperative class. Though, self efficacy is multidimensional and changes across particular activities within specific domain. Third, self-efficacy depends on mastery norm performance rather than normative or other measures. That is students beliefs about their skillfulness in doing a specific task such as writing an essay is measured and this gives no idea about comparing them with their peers ability in essay writing. As a final point, judgment about self efficacy is done before really doing the task.

\section{F. Self-efficacy and Academic Achievement}

Students' academic achievement is mainly manipulated by their cognitive abilities. That is students with greater intellectual capacity would be successful at higher level than students with lower intellectual competencies. Students' self-efficacy perceptions play a key role in decision about student academic performances. However academic achievement is related to many factors and just knowing and possessing skills does not guarantee success. Students meet many difficult situations in their learning such as noisy study environments, bothersome thoughts, and negative feelings and if they don't use their knowledge well in these circumstances they won't success. Bandura (1993) found that high self efficacious students tend to deal well with these circumstances and would better succeed from their peers with the same academic level ability. That is self efficacy will guarantee students academic achievements irrespective of their ability. Wong (2005) found that many language learners in ESL context also suffer from low self efficacy. He argues that numerous ESL students have poor learning strategies and low self efficacy which will diminish their motivation and consequently their language proficiency. Lack of learning strategies hinder their problem solving ability and low self efficacy impede their involvement in learning tasks.

Academic self-efficacy is related to issues, such as self-efficacy expectations, perceived self-competence, perceived control, academic self-regulatory skills. According to Bandura (1997) Self-efficacy expectations determine whether that person deals with hard conditions, the amount of attempt he will spend and the degree his efforts will continue in spite of difficulties and impediments. Bandura (1993) mentions that perceived self- competence is an inherent drive to feel competent. Having the required skills or knowledge alone cannot be useful in difficult conditions. In fact many individuals cannot use their skills in difficult situations. Self efficacy is an important factor in determining their success in difficult conditions. Students with similar ability will vary greatly in their efficacy to cope with academic demands. 
Perceived control (locus of control), is expressed along a continuum with an internal and external locus of control at the two ends. Meinhold and Mulkus (2005) express that in an internal locus of control, events are personally determined and one perceives that his actions will produce the desired outcome, whereas in an external locus of control, life outcomes are due to outside causes, such as fate and chance. In fact, self efficacy can predict students' use of cognitive and self regulative learning strategies in classroom situations. However these factors alone are not enough for directing one's performance in difficult situations. Bandura (1995) states that highly self-efficacious individuals apply different academic self regulatory skills like goal-setting, self evaluation, self monitoring, time planning, and strategy use.

Pajares (2002) put forward Bandura's (19860 idea of reciprocal determinism in school contexts. Teachers have the challenge for improving the academic learning and confidence of the students. Teachers can develop students' emotional state, to change their imperfect self beliefs and thinking patterns (personal factors), to develop their academic skills and self regularity strategies (behavior), and to modify school constructions to facilitate students' achievements (environmental factors). Self efficacy is not a judgment about physical characteristics or personality traits; it is a belief about what a person can do. Zimmerman (1995) mentioned that self efficacy is also context-specific and differs across subsequent elements:

- Level: level refers to the complexity of specific activity

- Generality: Generality refers to transferability of efficacy for specific task to different tasks or activities.

- Strength: Strength refers to the assurance about doing a task (Zimmerman, 1995)

\section{G. Educational Association of Self-efficacy}

Numerous studies found that self efficacy associates with academic success (Bandura, 1997; Shunk \& Pajares, 2002). Self efficacy also correlates with indexes of self-regulation, especially use of effective learning strategies. Self efficacy, self regulation, and cognitive strategy use are strongly related and can guess success (Shunk \& Pajares, 2002). Accordingly, as Pajares (2002) mentioned self efficacy is related to self regulated learning variables. High self efficacious students can use more cognitive and metacognitive strategies. The acquisition of cognitive skills, modeling effects and goal setting control the expansion of self efficacy beliefs and that these beliefs will affect academic performances.

\section{RESEARCH QUESTIONS}

As the literature shows students' self-efficacy beliefs play a significant function in understanding how a person would act in academic settings. There are lots of obstacles that students may face during learning and just equipping ones with knowledge and skills cannot guarantee that students will use them well in hard and complex situations. Self efficacy is a key predicator of student's success. That's encouraged the researcher to investigate the self efficacy of Iranian students. This study intended to examine the relationship of Iranian students' self efficacy and their language proficiency. This study seeks to answer the following questions:

1. Is there any relation between Iranian students' language proficiency and their self efficacy?

2. Do Iranian students with different majors (humanities, medicine and engineering) have different self efficacy?

3. Are there any differences between Iranian students' majors (humanities, medicine and engineering) and their language proficiency?

\section{METHOD}

\section{A. Participants}

The sample participating in this study consisted of 112 university students, majoring humanities at IAU Babol Branch, IAU Ghaemshahr branch and Babol University of Medical Sciences.

\section{B. Instruments}

Self efficacy questionnaire and Michigan Test of English Language Proficiency (MTELP) were used to measure the variables under study. Students' language achievement was measured by Michigan Test of English Language Proficiency (MTELP). MTELP was chosen because it is reliable and matches the proficiency level of university students. MTELP contains three parts: part one is a test of grammar which have 40 items, part two is a vocabulary test which consists of 40 items, and the last part contains four reading passages each with 5 questions. The self-efficacy questionnaire included 40 questions followed by 5 point likert scale choices. The self-efficacy questionnaire was adapted on the surveys of Albert Bandura.

\section{Procedure}

To examine the fist variable of this study student were supposed to answer a standardized Persian self efficacy questionnaire within 15 minutes. The questionnaire contains 40 questions followed by 5 point likert scale choices. The Persian version of the questionnaire was validated with 100 students from Ferdosi University, Mashhad. The score obtained from self efficacy questionnaire ranges from 0 to 200. For measuring students' language proficiency Michigan Test of English Language Proficiency was administered. Students had 90 minutes to do the test. The MTELP ranges from 0-100. 


\section{Design}

This study was not an experimental research it is a descriptive one. As mentioned by Seliger and Shohami (1989) descriptive study provides descriptions of naturally occurring phenomena connected with language learning. It will give information about naturally happening phenomenon with no control over any variables. Thus this study has an Ex-Post Facto design since the researcher does not manipulate what has happened to the participants of the current research. Accordingly, in this study students' language achievement is taken as dependent variables and students' self efficacy and their majors (humanities, medicine and engineering) are taken as independent variable.

\section{DATA ANALySIS AND RESUlts}

In order to answer the questions the researcher used Statistical Software for Social Sciences (SPSS). The first research question is intended to find the relation of Iranian students' language proficiency level and their self efficacy. In order to find the relation between these two variables Pearson Correlation Coefficient was used. It will show how much theses two variables are related. (See the table1)

TABLE1.

PEARSON CORRELATION OF LANGUAGE PROFICIENCY AND SELF EFFICACY

\begin{tabular}{|ll|l|l|}
\hline & $\begin{array}{l}\text { Language } \\
\text { proficiency }\end{array}$ & self efficacy \\
\hline Language proficiency & Pearson Correlation & 1 & $.788^{* *}$ \\
& Sig. (2-tailed) & .000 \\
& $\mathrm{~N}$ & 112 & 112 \\
\hline self efficacy & Pearson Correlation & $.788^{* *}$ & 1 \\
& Sig. (2-tailed) & .000 & 112 \\
\hline $\mathrm{N}$ & 112 & \\
\hline
\end{tabular}

As shown in table1 the correlation coefficient is 0.78 which is significant at $p<0.01$. This means that there is a positive correlation between students' language proficiency and their self efficacy Students with higher self efficacy tend to have higher language achievement. Second research question aimed at investigating the difference between students' major and their self efficacy. Since we had three different majors we used One-Way ANOVA to compute the differences of these groups.

TABLE 2

ANOVA RESULTS ON THE SELF EFFICACY LEVEL

\begin{tabular}{|l|l|l|l|l|l|}
\hline \multicolumn{1}{|l|}{ Self efficacy } & Sum of Squares & df & Mean Square & F & Sig. \\
\hline Between Groups & 4506.371 & 2 & 2253.185 & 14.439 & .000 \\
Within Groups & 17009.486 & 109 & 156.050 & & \\
Total & 21515.857 & 111 & & & \\
\hline
\end{tabular}

The results of one-way as shown in Tables 2 reveal that there are significant differences among students' majors and their self efficacy level, that is the significant is 0.00 which is smaller than 0.05 and 0.01 , so the difference between the groups are significant. As post hoc table shows the mean differences are significant (Sig. $=.000)$ between humanities, medicine and humanities, engineering, but no statistically significant differences can be found in other comparisons.

TABLE 3.

SCHEFFE TEST ON SELF EFFICACY SCORE

Scheffe

\begin{tabular}{|c|c|c|c|c|c|c|}
\hline \multirow[b]{2}{*}{ (I) major } & \multirow[b]{2}{*}{$(\mathrm{J})$ major } & \multirow{2}{*}{$\begin{array}{c}\text { Mean Difference (I- } \\
\mathrm{J})\end{array}$} & \multirow[b]{2}{*}{ Std. Error } & \multirow[b]{2}{*}{ Sig. } & \multicolumn{2}{|c|}{$95 \%$ Confidence Interval } \\
\hline & & & & & Lower Bound & Upper Bound \\
\hline \multirow[t]{2}{*}{ humanities } & medicine & $-12.49432^{*}$ & 3.09925 & .001 & -20.1860 & -4.8027 \\
\hline & engineering & $-14.64990^{*}$ & 2.83708 & .000 & -21.6909 & -7.6089 \\
\hline \multirow[t]{2}{*}{ medicine } & humanities & $12.49432^{*}$ & 3.09925 & .001 & 4.8027 & 20.1860 \\
\hline & engineering & -2.15559 & 2.86300 & .754 & -9.2609 & 4.9497 \\
\hline \multirow[t]{2}{*}{ engineering } & humanities & $14.64990^{*}$ & 2.83708 & .000 & 7.6089 & 21.6909 \\
\hline & medicine & 2.15559 & 2.86300 & .754 & -4.9497 & 9.2609 \\
\hline
\end{tabular}

For testing the third question which examined the difference between students' major and their language achievement One -Way ANOVA was utilized. 
TABLE 4.

ANOVA RESULTS ON LANGUAGE PROFICIENCY

\begin{tabular}{|c|c|c|c|c|c|}
\hline & Sum of Squares & $\mathrm{df}$ & Mean Square & $\mathrm{F}$ & Sig. \\
\hline Between Groups & 1549.962 & 2 & 774.981 & 7.374 & .001 \\
\hline Within Groups & 11454.895 & 109 & 105.091 & & \\
\hline Total & 13004.857 & 111 & & & \\
\hline
\end{tabular}

As shown in the above table the differences between students' major and language proficiency are significant at 0.05 and 0.01 levels. To have a better picture of the differences among groups a post hoc analysis is used. The results of post hoc shows there are significant differences between language proficiency of humanities' students with Medicine and Engineering students.

TABLE 5.

SCHEFFE TEST ON SELF EFFICACY SCORE

\begin{tabular}{|c|c|c|c|c|c|c|}
\hline \multirow[b]{2}{*}{ (I) major } & \multirow[b]{2}{*}{$(\mathrm{J})$ major } & \multirow{2}{*}{$\begin{array}{l}\text { Mean Difference (I- } \\
\text { J) }\end{array}$} & \multirow[b]{2}{*}{ Std. Error } & \multirow[b]{2}{*}{ Sig. } & \multicolumn{2}{|c|}{$95 \%$ Confidence Interval } \\
\hline & & & & & Lower Bound & Upper Bound \\
\hline \multirow[t]{2}{*}{ humanities } & medicine & $-8.094697^{*}$ & 2.543355 & .008 & -14.40672 & -1.78267 \\
\hline & engineering & $-8.203740^{*}$ & 2.328206 & .003 & -13.98182 & -2.42566 \\
\hline \multirow[t]{2}{*}{ medicine } & humanities & $8.094697^{*}$ & 2.543355 & .008 & 1.78267 & 14.40672 \\
\hline & engineering & -.109043 & 2.349481 & .999 & -5.93992 & 5.72183 \\
\hline \multirow[t]{2}{*}{ engineering } & humanities & $8.203740^{*}$ & 2.328206 & .003 & 2.42566 & 13.98182 \\
\hline & medicine & .109043 & 2.349481 & .999 & -5.72183 & 5.93992 \\
\hline
\end{tabular}

\section{CONCLUSION AND Limitation OF STUdy}

Most studies confirm that self efficacy can enhance students' achievement. The relationship between self efficacy and language learning has been studied by many researchers. Rahimi and Abedini (2009) studied Iranian students' self efficacy and their listening skills and found a positive correlation. Magogwe and Oliver (2007) also reported a positive relation between self efficacy and language learning strategies. The results of present study are in line with previous studies which reported a positive relation between self efficacy and academic achievement. The present study validates previous studies which focus on self efficacy as a predicator of academic achievements (Bandura 1997; Pajares, 2000). The results of present study show that self efficacy and language proficiency are strongly correlated. The result is also in line with Rahemi (2007). Rahimi found that Iranian high school students majoring humanities have low self efficacy and hence low language proficiency. This study also demonstrated that humanity students have lower self efficacy and also lower language proficiency comparing to engineering and medicine students. It can be concluded that highly self efficacious learners tend to have better perception of their capabilities and therefore try harder to reach their goals.

As Cotteral (1999) mentioned self efficacy is learners' self assurance in their general ability in accomplishing a specific language goals. Language teachers should improve students' self efficacy. In fact teachers should support learners to expand their self efficacy even before really doing a task and this can be very helpful for learners' to have a good language learning experiences. Pajares (2002) mentioned that one way that teachers can increase students' self efficacy in academic setting is through peer modeling. If individuals see a successful student who is like them, this would give them an optimistic view about their own capabilities, and this would have a significant influence on students' self efficacy. Such a high efficacy belief will make students to put more effort in accomplishing their desired goals. He also mentioned that social messages that adults receive can also enhance their self efficacy. Expressing positive views about their capabilities can really be helpful in increasing students' self efficacy and reducing their stress. So teachers as well as parents should remind students of their competences and encourage them to put more effort in the process of language learning.

\section{REFERENCES}

[1] Bandura, A. (1977). Social learning theory. New Jersey: Prentice-Hall.

[2] Bandura, A. (1986). Social foundations of thought and action: A social cognitive theory. New Jersey: Prentice-Hall.

[3] Bandura, A. (1989). Human agency in social cognitive theory. American Psychologist 44. 9, 1175- 1184.

[4] Bandura, A. (1993). Perceived self-efficacy in cognitive development and functioning. Educational Psychologist 28. 2,117148.

[5] Bandura, A. (1995). Self-efficacy in changing societies. Cambridge: Cambridge University Press.

[6] Bandura, A. (1997). Self-efficacy: The exercise of control. New York: Freeman.

[7] Chastain, K. (1988). Developing second language skills theory and practice ( ${ }^{\text {rd }}$ edn.). San Diego: Harcourt Brace Jovanovich. 
[8] Cotterall, S. (1999). Key variables in language learning: What do learners believe about them? System 27. 4, $493-513$.

[9] Dewitz, S. J., \& Walsh, B. (2001). Self-efficacy and college student satisfaction. Journal of Career Assessment 10.3, 315-326. doi: $10.1177 / 10672702010003003$.

[10] Jing, H. (2006). Learner resistance in metacognitive training? An exploration of mismatches between learner and teacher agendas. Language Teaching Research 10.1, 95- 117. doi: 10.1177/136216880601000107.

[11] Magogwe, J. M. \& Oliver, R. (2007). The relationship between language learning strategies, proficiency, age and self-efficacy beliefs: A study of language learners in Botswana. System 35.3, 338-352. doi:10.1016/system.2007.01.003.

[12] Meinhold, J. L., \& Malkus, A. J. (2005). Adolescent environmental behaviors: Can knowledge, attitudes, and self-efficacy make a difference? Environment and Behavior 37.5, 511- 532. doi: 10.1177/0013916504269665.

[13] Pajares, F. (2000). Self-efficacy beliefs and current directions in self-efficacy research. from http://www.emory.edu/EDUCATION/mfp/effpage.html (accessed 20/3/2012).

[14] Pajares, F. (2002). Overview of social cognitive theory and self-efficacy. Retrieved December 2012 from http:// www.uky.edu/ eushe2/Pajares/eff.html (accessed 17/7/2012).

[15] Pajares, F. (2005). Self-efficacy during childhood and adolescence: Implications for teachers and parents. http://www.uky.edu/ eushe2/Pajares/PajaresAdoed2006.pdf (accessed 17/5/2012).

[16] Pajares, F., \& Schunk, D. H. (2001). Self-beliefs and school success: Self-efficacy, self-concept, and school achievement. In R. Riding, \& S. Rayner (eds.), Self-perception. London: Ablex Publishing, 239- 266.

[17] Rahemi, J. (2007). Self-efficacy in English and Iranian senior high school students majoring in humanities. Novitas-ROYAL 1.2, 98-111.

[18] Rahimi, A. \& Abedini, A. (2009). The interface between EFL learners' self-efficacy concerning listening comprehension and listening proficiency. Novitas-ROYAL 3.1, 14-28.

[19] Schunk, D.H. (1991). Self-efficacy and academic motivation. Educational Psychologist, 26, 207-231.

[20] Schunk, D. H., \& Pajares, F. (2002). The development of academic self-efficacy. In A. Wigfield, \& J. Eccles (eds.), Development of achievement motivation. San Diego: Academic Press, 16-31.

[21] Seliger, H. W., \& Shohamy, E. (1989). Second language research methods. Oxford: Oxford University Press.

[22] Spratt, M., Humphreys, G., Chan, V. (2002). Autonomy and motivation: Which comes first? Language Teaching Research 6, 245-266. doi: 10.1191/1362168802/r106oa.

[23] Wong, M. S. L., (2005). Language learning strategies and language self efficacy: Investigating the relationship in Malaysia. RELC Journal 36.3, 245-269. doi: 10.1177/0033688205060050.

[24] Zimmerman. B. J., \& Cleary, T. J. (2006). Adolescents' development of personal agency: The role of self-efficacy beliefs and self-regulatory skills. In F. Pajares, \& T. Urden (eds.), Self-efficacy beliefs of adolescents. Greenwich, CT: Information Age Publishing, 45-69.

Atefeh Nasrollahi is a PhD. Student in Islamic Azad University Science and Research Branch, Tehran. She is now faculty member of Islamic Azad University Ayatollah Amoli Branch. She has published papers in international journals. Her main areas of interests are first language acquisition, learning styles, literature teaching.

Hamed Barjasteh is a PhD student in Islamic Azad University Science and Research Branch, Tehran. He has published many articles in Iranian and international journals. His areas of interest include, language learning strategies, learner's characteristics and critical thinking. He is now the head of English department in Islamic Azad University ayatollah Amoli Branch 